\title{
Effect of Gurney Flap Height and Mounting Position on the Performance of a Centrifugal Fan
}

\author{
M. Suresh ${ }^{1}$ and N. Sitaram ${ }^{2 \dagger}$ \\ ${ }^{1}$ IIT Madras, Chennai, India. Present Address: Senior Design Analyst, SBES Technologies (P) Ltd., 28-4- \\ 26/7, Santhinagar 2nd Road, Eluru - 534007, India \\ ${ }^{2}$ Department of Mechanical Engineering Indian Institute of Technology Madras, Chennai - 600 036, India
}

†Corresponding Author Email: nsitaram.iitm@gmail.com

\begin{abstract}
The effect of Gurney flap height and mounting position on the head coefficient of a centrifugal fan at different Reynolds numbers is investigated experimentally. Quarter round Gurney flap of 1.0, 1.5, 2.0 and 2.5 $\mathrm{mm}$ height is mounted at three different positions, $\mathrm{S}=1.00$ (impeller tip), $\mathrm{S}=0.95$ and $\mathrm{S}=0.90$ on the pressure surface of the impeller blade tip. Performance tests are carried out on the centrifugal fan at five Reynolds numbers corresponding to five rotational speeds of 1100, 1500, 2000, 2500 and $2900 \mathrm{rpm}$ respectively. From the performance curves it is found that the fan head coefficient increases significantly with Gurney flaps at low Reynolds numbers and increases marginally at high Reynolds numbers. Effect of Reynolds number on the head coefficient is considerable for the baseline fan and found to be negligible for the fan with Gurney flaps, for all combinations of Gurney flap mounting position and height. The head coefficient of the fan improves as Gurney flap height increases but the improvement is marginal after certain height of Gurney flap. The head coefficient of the fan deteriorates when Gurney flap is mounted away from the impeller blade tip.
\end{abstract}

Keywords: Centrifugal fan; Gurney flap; Gurney flap height; Gurney flap mounting position; Reynolds number; Head coefficient; Flow coefficient.

\section{NOMENCLATURE}

$\begin{array}{ll}\text { A } & \text { cross sectional area } \\ \mathrm{b}_{2} & \text { blade height at exit } \\ \mathrm{C} & \text { velocity } \\ \mathrm{CFD} & \text { Computational Fluid Dynamics } \\ \mathrm{Ch} & \text { chord } \\ \mathrm{D}_{2} & \text { impeller tip diameter } \\ \mathrm{GF} & \text { Gurney Flap } \\ \mathrm{h} & \text { Gurney flap height } \\ \mathrm{N} & \text { speed } \\ \mathrm{p} & \text { pressure } \\ \mathrm{Q} & \text { volume flow } \\ \mathrm{Re}_{\mathrm{b} 2} & \text { Reynolds number based on } \mathrm{b}_{2} \\ \mathrm{r}_{\mathrm{GF}} & \text { radius where Gurney flap is mounted } \\ \mathrm{r}_{2} & \text { impeller tip radius } \\ \mathrm{S} & \text { Gurney flap mounting position } \\ \mathrm{s}_{2} & \text { blade spacing at impeller tip } \\ \mathrm{U} & \text { blade speed } \\ \mathrm{W} & \text { specific work } \\ \mathrm{Z} & \text { height difference between suction and } \\ & \text { delivery sides of the fan }\end{array}$

\begin{tabular}{|c|c|}
\hline$\alpha$ & coefficient of discharge \\
\hline$\Delta \phi_{\max }$ & $\begin{array}{l}\text { percentage change in maximum } \\
\text { flow coefficient }\end{array}$ \\
\hline$\Delta \phi_{\text {peak }}$ & $\begin{array}{l}\text { percentage change in flow } \\
\text { coefficient at peak head coefficient }\end{array}$ \\
\hline$\Delta \psi_{\text {design }}$ & $\begin{array}{l}\text { percentage change in head } \\
\text { coefficient at design condition }\end{array}$ \\
\hline$\Delta \psi_{\text {peak }}$ & $\begin{array}{l}\text { percentage change in peak head } \\
\text { coefficient }\end{array}$ \\
\hline$\phi$ & flow coefficient $\left(\mathrm{Q} / \pi \mathrm{D}_{2} \mathrm{~b}_{2} \mathrm{U}_{2}\right)$ \\
\hline$\phi_{\max }$ & maximum flow coefficient \\
\hline$\rho$ & density of air \\
\hline$v$ & kinematic viscosity \\
\hline$\psi$ & head coefficient $\left(2 \mathrm{~W} / \mathrm{U}_{2}{ }^{2}\right)$ \\
\hline$\psi_{\text {design }}$ & $\begin{array}{l}\text { head coefficient at design flow } \\
\text { coefficient }\end{array}$ \\
\hline$\psi_{\text {peak }}$ & peak head coefficient \\
\hline \multicolumn{2}{|l|}{ Subscripts } \\
\hline $\mathrm{d}$ & delivery side of the fan \\
\hline $\mathrm{s}$ & suction side of the fan \\
\hline
\end{tabular}




\section{INTRODUCTION}

Industrial fans are basically of two types: axial and centrifugal. They are widely used for cooling, ventilation, vacuuming and dust removal, inflating, etc., and account for a large fraction of the worldwide industrial energy demand. Centrifugal fans are used in these applications, because of low cost, ease of fabrication, robustness, higher pressure ratio and reasonable design and off-design efficiency. The range of application of centrifugal fans has been extended to cool portable electronic devices where they have to be run at very low Reynolds numbers (Tamagawa et al. 2006) or low rotational speeds. Other examples include computer cooling fans, refrigeration fans, air conditioning fans and automotive cooling fans as they are suitable when space is limited and when there is a high pressure drop environment. Because of their relatively low rotational speeds in these applications, the fan efficiency is reduced.

In recent years, it has been recognized that effective energy conservation can play a major role in reducing energy consumption and can thus offset growth in energy supply required to keep up with industrial demand. Given large fraction of the energy consumed by fans, even modest improvements applied at large scales could result in significant energy savings. Hence there is a need to improve the head coefficient of centrifugal fans at low Reynolds numbers.

A simple and inexpensive passive means that had shown improved aerodynamic performance of aerofoils and wings is Gurney flap (GF). Gurney flap is not a sophisticated device. It is simply a short flat tab or plate attached to the trailing edge perpendicular to the chord line on the pressure side of an airfoil or a wing. Dan Gurney first used this type of flap in 1971 on his race car to increase the down force and traction of his car. Gurney flaps are now used widely on airfoils, subsonic and supercritical wings, high lift devices, delta wings, turbomachinery blades, wind turbine blades and helicopters rotors. Gurney flaps can be retrofitted in these applications. A review on their scope of applications in these devices is given by Wang et al. (2008).

Effect of Gurney flap on a low-speed airfoil was investigated by Liebeck (1978) on a Newman airfoil and Li et al. (2002) on a NACA0012 airfoil. They concluded that Gurney flap substantially increases the lift coefficient. Gurney flap increases the effective camber of the airfoil and the stall angle is reduced. The zero-lift angle of attack becomes increasingly more negative with an increase in Gurney flap height. Gurney flap height typically ranges from less than $1 \%$ to about $5 \%$ of the chord of an airfoil. When the height of Gurney flap exceeds more than $2 \%$ of the chord the drag coefficient of airfoil abruptly increases (Giguere et al. 1997). Giguere et al. (1997) suggested that the optimum Gurney flap height for best lift-to-drag ratio is determined by the flow condition at the trailing edge on the pressure side of airfoil. Also the flap should be submerged in the boundary layer. Boundary layer thickness, $\delta$ on a flat plate is given by the relation $\delta \sim \mathrm{Ch}(\mathrm{Re})^{-1 / 2}$ taking $\mathrm{Ch}$ as the chord of an airfoil. Boundary layer thickness $\delta$ increases as Reynolds number decreases. Hence the optimum height of the flap will be different at different Reynolds numbers. Brown and Filippone (2003) estimated the optimum Gurney flap height, $\mathrm{h}_{\mathrm{opt}}=37.155\left(\mathrm{Ch}^{0.8} / \mathrm{C}^{0.2}\right) 10^{3}$.

Instantaneous flow patterns around Gurney flap by Troolin et al. (2006) and Gai and Palfrey (2003) on an airfoil show a wake containing an alternatively shed Karman vortex sheet. The time averaged velocity profile concluded that the wake downstream the flap consisting of a pair of counter-rotating vortices is turned downwards. An off-surface stagnation point downstream of the trailing edge is also present. The presence of a pair of counter-rotating vortices downstream Gurney flap results in low pressure there, which reduces the adverse pressure gradient near the trailing edge of the airfoil. This leads to a delay or elimination of flow separation over the suction surface of the airfoil accompanied by a reduction in the boundary layer thickness. The vortices also increase the velocity over the suction surface, which in turn increase the suction on the rear body. On the other hand, the flow velocity upstream of Gurney flap is reduced and the pressure on the pressure surface of rear body is thus increased. The net effect of suction increase on the suction surface and pressure increase on the pressure surface leads to an increase in the total circulation of the airfoil, increasing lift by Gurney flap.

Traub had systematically examined the effects of Gurney flap on airfoils, elliptic airfoil, delta wing and wing sweep. He had varied many important parameters of Gurney flap, such as Gurney flap height, thickness, location from the trailing edge, mounting angle, gap between airfoil surface and Gurney flap and Reynolds number.

Traub (2017) tested effects of Gurney flap height and position on the lift enhancement of an elliptic airfoil at two Reynolds numbers. These results are presented and discussed in Fig. 1d. Traub et al. (2006) examined the effects of Gurney flap height, inclination angle, porosity, and distance (gap) from the surface. The limited data shows that the lift increases linearly with Gurney flap height, but decreases nearly linearly with Gurney flap gap and porosity. Similar results were presented by Lee (2009) for a perforated Gurney flap. Graham et al. (2018) have tested an airfoil with four values of Gurney flap heights $(0,1,2$ and $4 \%$ of chord) and four values of Gurney flap thicknesses $(1,2,4$ and $6 \%$ of chord). They found that maximum lift coefficient, lift coefficient at zero angle of attack decrease with Gurney flap thickness while maximum lift to drag ratio and minimum drag coefficient with Gurney flap thickness.

Though many studies have been carried out on airfoils and wings, application of Gurney flaps to turbomachinery has been very recent and explanation for the effect of Gurney flap on rotating machines is not sufficiently understood. Janus (2000) conducted numerical analysis with fan 
blades in two dimensional linear cascade models and concluded that flow separation on suction surface decreased and pressure rise also increased with Gurney flap. Byerley et al. (2003) and Chen et al. (2010) applied Gurney flaps on turbine cascades. Byerley et al. (2003) experimentally found that Gurney flaps delayed or eliminated laminar separation on suction surface of low pressure turbine blades. With Gurney flap, profile loss and exit velocity increased and flow turned toward the suction surface compared to turbine blade without Gurney flap. Chen et al. (2010) numerically found that Gurney flap weakened the adverse pressure gradient on the suction side and reduced the separation bubble thickness. Transition onset was delayed with Gurney flap. They numerically investigated the effect of three configurations of Gurney flap, viz. round, square and smooth convex types. Both round and square Gurney flaps gave nearly identical performance while smooth convex Gurney flaps giving slightly lower performance. Tatpatti et al. (2021) had carried out extensive computational investigations on different types of Gurney flaps (Flat, Quarter round, Half round and Triangular) of different height applied to T106 turbine blade used in low pressure (LP) turbine of aircraft gas turbines. The computations were carried out at five Reynolds numbers to identify best configuration and optimum height. The blades were tested in a cascade with flat and quarter round Gurney flaps of optimum height at five Reynolds numbers. The experimental static pressure distribution and total pressure loss coefficient agreed well with the computational results.

Myose et al. (1996) conducted flow visualization study with Gurney flap in compressor cascade at low Reynolds number and showed that Gurney flap delayed the stall at large incoming flow angles. Greenblatt (2011) used large Gurney flaps in an axial fan and studied about the effect of height and thickness of Gurney flap. Fan with Gurney flap produced higher non-dimensionalised pressure rise than baseline case in all flow rate range. Because addition of Gurney flap gave extra weight to fan blade, thin Gurney flap increased static efficiency most. Efficiency was lower at low Reynolds number but maximum efficiency increased with Gurney flaps. Chen et al. (2018) had carried out extensive computational and experimental investigations on a low speed axial flow fan with Gurney flaps of different heights. The fan with blades having Gurney flap always produced higher pressure rise, which increases with the height of the Gurney flap. However both static and total pressure efficiencies for fan with Gurney flap are reduced compared with those of the fan without Gurney flap. Dundi et al. (2012) investigated the effect of Gurney flap on a centrifugal fan with different Reynolds numbers. Energy coefficient increased with Gurney flap, dominantly at low Reynolds number and maximum flow rate slightly increased for the fan with a Gurney flap. Based on the encouraging results of Dundi et al. (2012) further investigations were undertaken to optimize the height of Gurney flap by Suresh and Sitaram (2014) for application in centrifugal fans and found that there is an optimal Gurney flap height at which performance of the fan increases substantially. Kim et al. (2013 and 2014) had recently applied a 5\% chord height Gurney flap to the tip of a radial fan impeller for an air conditioner fan. The aerodynamic performance of the radial fan was investigated by using experimental and numerical methods. They showed that both head coefficient and efficiency were increased by $26.8 \%$ and $5.6 \%$ at the design flow coefficient of 0.138 when Gurney flap was used. Suresh and Sitaram (2019) had used Gurney flaps of different configurations, namely, angle/flat, half round and quarter round profiles and found that quarter round Gurney flaps gave slightly improved performance. Son et al. (2017) patented a twisted type Gurney flap for application to the centrifugal fan for air conditioners. It is interesting to note that Gurney flaps are also found to improve the performance of transonic axial flow compressor rotors (Mudassir Ahmed et al. 2014 and Mudassir Ahmed and Nagpurwala 2016) at relatively high Reynolds numbers. Computational studies were carried out on a transonic rotor with $1 \mathrm{~mm}$ Gurney flap attached to the pressure surface of the blade at the trailing edge (Mudassir Ahmed et al. 2014). The Gurney flap length was varied 20 to $100 \%$ of span from rotor tip. The Gurney flap with $100 \%$ span improved the pressure ratio by $4.6 \%$ without any change in isentropic efficiency. Computations were also carried out (Mudassir Ahmed and Nagpurwala 2016) on a transonic axial compressor stage. The pressure ratio was improved with a drop in efficiency. It can be expected that Gurney flap will further improve the performance of transonic axial and centrifugal compressors of gas turbine engines of aircraft, which normally operate at high altitudes, with Reynolds numbers as low as 25,000. Mudassir Ahmed and Nagpurwala (2018) had carried out computations on a transonic axial rotor with Gurney flap placed at $92.7 \%, 96.4 \%$ and $100 \%$ rotor blade tip chord from leading edge. All Gurney flap mounting positions had shown higher pressure rise compared to the configuration without Gurney flap. But the pressure rise decreases as Gurney flap moved away from the trailing edge. The trailing edge of a transonic axial compressor rotor blade is very thin. Hence Gurney flap must be placed away from the trailing edge for structural integrity.

Wind turbines are receiving a lot of research attention to improve their performance using various devices. Gurney flap is a very simple device which can be attached to airfoils for various applications including wind turbines. Zhang et al. (2019) used CFD to investigate the performance improvement capabilities of Gurney flap for a two bladed horizontal axis wind tunnel. A Gurney flap fixed on the rotor blade pressure surface from rotor hub (0.35 times casing radius) to 0.46 times casing radius. The rotor speeds are 350 and 485 resulting in high tip Reynolds numbers of 2.5 to $3.5 \times 10^{6}$. Gurney flaps of heights of 10 and $20 \mathrm{~mm}$ are fixed at $85 \%$ chord location at an angle of $55^{\circ}$. The computational results indicate that the power output increased by $21 \%$. These results are very promising for the application of Gurney flaps to wind turbines. Chakroun and Bangga (2021) numerically 
investigated the effect of Gurney flap on the power output of a two bladed H-Darrius vertical axis wind turbine. They demonstrated that the optimum height is $6 \%$ of chord in contrast to the limit of height of Gurney flap of $2 \%$ chord for static airfoils. Similar result of optimum Gurney flap height of $3 \%$ of chord were computationally demonstrated for a three straight bladed vertical axis wind turbine by Syawitri et al. (2020). However the experimental studies by Bao et al. (2000) demonstrated the optimum height of Gurney flap as $2 \%$ of chord of a NACA $63_{2}-215$ aerofoil for use with wind turbine. The angle of attack is varied from 0 to $40^{\circ}$, the height of Gurney flap varied from 1 to $2.5 \%$ of chord, the mounting angle of Gurney flap is varied from 0 to $135^{\circ}$.

From the above discussion of Gurney flap application in turbomachinery components and centrifugal fans, no work has been done on the effect of mounting position of Gurney flap in these applications except by Mudassir Ahmed and Nagpurwala (2018).

The performance improvement using Gurney flap depends on many geometric parameters of Gurney flap. Most important among them are height, configuration, position and mounting angle. Gurney flaps are very effective at low Reynolds numbers. However the experiments had shown that Gurney flaps were also effective for flow over airfoil at high Reynolds numbers (Li et al. 2003). Airfoils for some applications have small chords with very thin trailing edges. Hence it may not be possible to mount Gurney flaps at the trailing edge. Gurney flap has to be mounted upstream of the trailing edge. Li et al. (2003) carried out experiments on the effect of mounting position on the performance of NACA0012 airfoil. Their results are shown in Fig. 1a. Gurney flap increases lift coefficient even when it was mounted upstream of the trailing edge. Only at an angle of attack of 14 degrees, airfoil with Gurney flap mounted upstream of the trailing edge ( $\mathrm{S}=0.94$ to 0.98 ) showed reduced lift coefficient. This is because at this angle, the airfoil with Gurney flap stalls, while the airfoil without Gurney flap stalls at 16 degrees. In some applications, deployed Gurney flap are mounted on the pressure surface of the airfoils to actively change the height of Gurney flaps depending on the working conditions (Wang et al. 2008). Gurney flaps are to be mounted upstream of the airfoil trailing edge to actuate them. These results are shown in Fig. 1b. In both cases, it is evident that Gurney flap position reduces lift enhancement. Maughmer and Bramesfeld (2008) had presented linear enhancement with Gurney flap position for $\mathrm{S} 903$ airfoil for wind turbines, while $\mathrm{Li}$ et al. (2003) presented linear enhancement of lift coefficient initially followed by flatter response as Gurney flap is moved away from the trailing edge. However later investigations by Cole et al. (2013) presented contradictory results. While the lift enhancement capacity decreases as Gurney flap is moved upstream of the airfoil trailing edge, this value is negative in some cases, when Gurney flap is mounted at $\mathrm{S}=0.90$ or lesser. Their results are shown in Fig. 1c. Traub (2017) tested an elliptical aerofoil with Gurney flap at two Reynolds numbers with 1, 2 and 4\% Gurney flap height and the location of Gurney flap varying from trailing edge to 0.913 chord. His results of $\mathrm{C}_{\mathrm{LMAX}}$ and (L/D) $)_{\mathrm{MAX}}$ are presented in Fig. 1d. Maximum lift coefficient increases with Reynolds number. It is interesting to observe that maximum lift coefficient increase at the position of Gurney flap moves away from the trailing edge to $\mathrm{X} / \mathrm{Ch}=0.913$. The reason cited him is that Gurney flap submerged in the separated boundary layer near the trailing edge makes them ineffective except the largest Gurney flap. At lower Reynolds number, (L/D) $)_{\text {MAX }}$ increases slightly with the Gurney flap height for all chordwise positions of Gurney flap at the lower Reynolds number. However at the higher Reynolds number, (L/D) MAX $_{\text {. }}$ drops rapidly for $4 \%$ height Gurney flap for all positions of Gurney flap due to pressure drag penalty across Gurney flap. The drop is negligible for Gurney flap near the trailing edge and increases as the flap moves away from the trailing edge. Uneo (2010) presented experimental results with Gurney flap height (2 and $4 \%$ of chord) and position $(\mathrm{S}=0.85,0.90,0.95$ and 1.00$)$ of Gurney flaps on the lift coefficients of NACA 4424 airfoil at angles of attack varying from -4 to 6 degrees and at Reynolds numbers from 1.0 to $1.8 \times 10^{5}$. He had shown that a $2 \%$ Gurney flap at $85 \%$ chord had the highest performance in terms of lift change $\left(\Delta \mathrm{C}_{\mathrm{L}}\right)$ in the range of -4 to +6 degrees angle of attack. In all cases, for any given flap height, Gurney flap at $100 \%$ chord was found to always have the lowest lift change. From this comprehensive study on a single airfoil, it seems that a Gurney flap mounted upstream of the airfoil trailing edge is advantageous. His results are presented in Fig. 1e. Jain et al. (2015) carried out computational studies on the NACA0012 airfoil tested by Li et al. (2003) and presented similar trends upto the stall angle of attack. Their results presented in Fig. 2 show that the extent of recirculating vortex increases when Gurney flap is mounted at $\mathrm{S}=0.90$, resulting in loss of lift enhancement capability. The streamlines are less deviated from the trailing edge direction compared to the streamlines when Gurney flap is mounted at $\mathrm{S}=1.00$.

From the work done by various researchers and as discussed above Gurney flap height and mounting position place a vital role in increasing the aerodynamic efficiency of airfoils and wings. Though application of Gurney flaps in centrifugal fan impeller blade is very recent, effect of Gurney flap height and mounting position has not been reported in the literature to the best of the knowledge of the authors. Hence the present work is undertaken to study the effect of varying the mounting position of Gurney flap on a centrifugal fan pressure rise and operating range.

The results of the present investigation have applications for low Reynolds number centrifugal fans used in many commercial applications such as cooling, ventilation, vacuuming and dust removal, inflating, etc. The thickness of the impeller blades, which are usually made of low strength plastics, of these centrifugal fans is very small, about $0.5 \mathrm{~mm}$. 

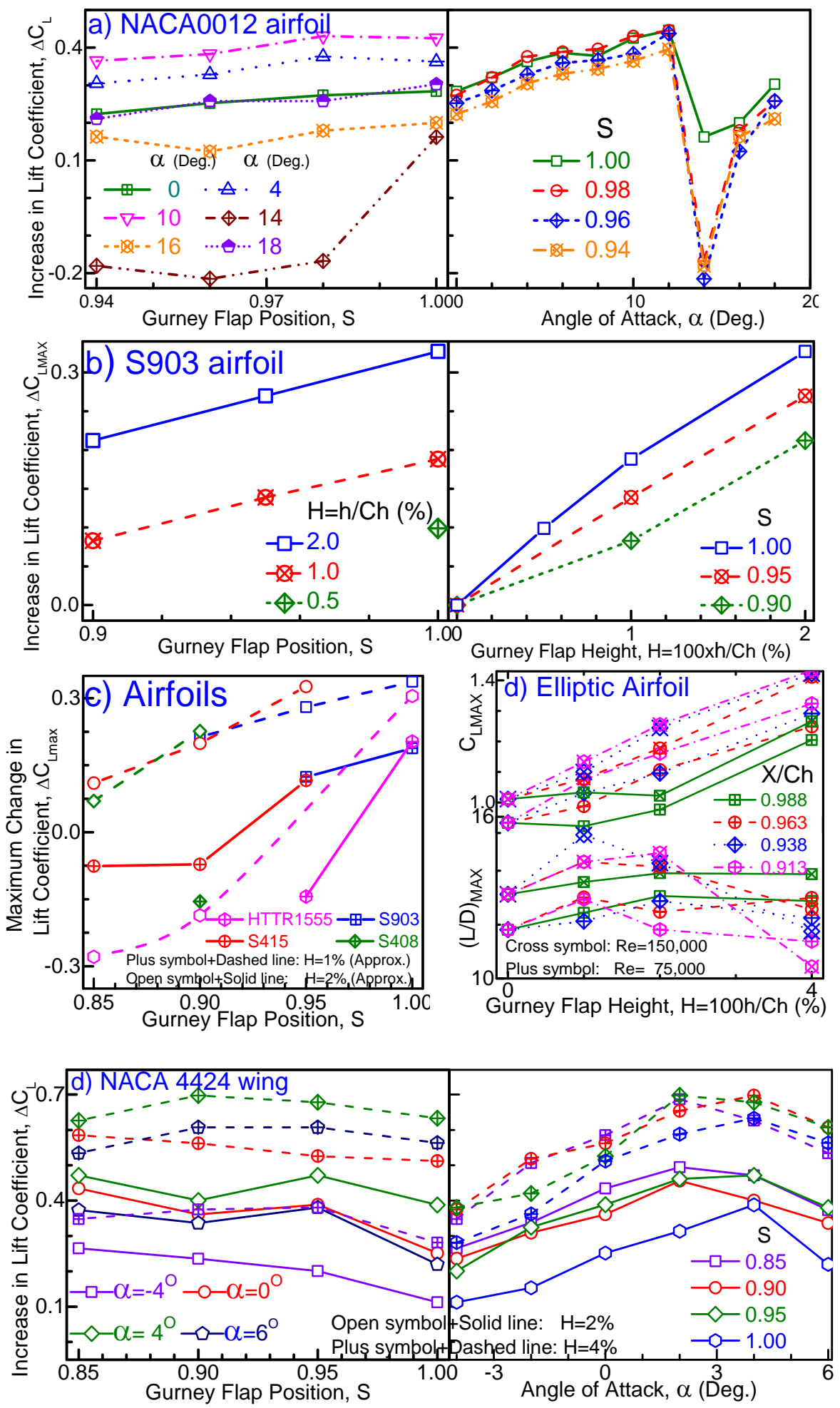

Fig. 1. Effect of Gurney flap mounting postion on the lift enhancement capacity by various researchers adopted from (a) Li et al. (2003), (b) Maughmer and Bramesfeld (2008), (c) Cole et al. (2013), (d) Traub (2017), (e) Uneo (2010). 

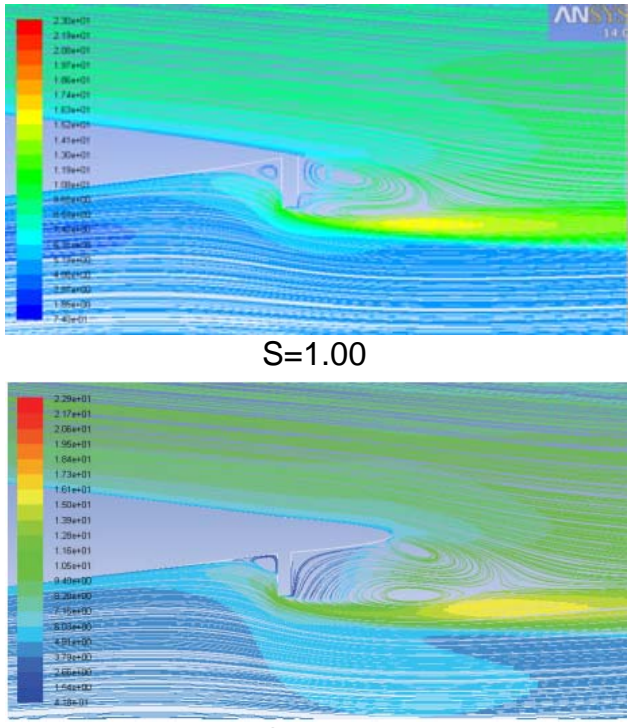

$S=0.96$

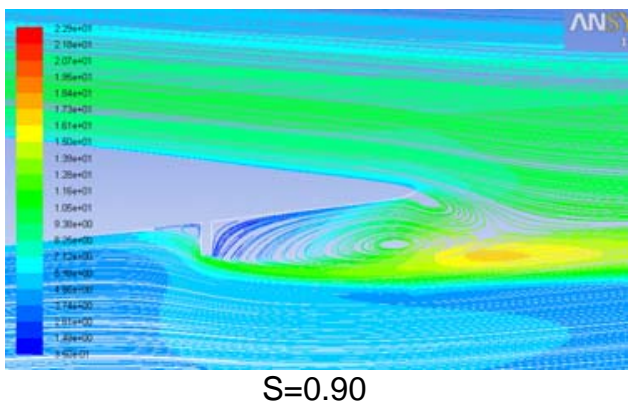

Fig. 2. Pathlines and turbulence intensities for different positions with a Gurney flap of $1.5 \%$ chord height at $\alpha=12^{\circ}$ (Jain et al. 2015).

Hence it may not be possible to mount Gurney flaps at the tip of the impeller blade due to strength limitation. Gurney flaps have to be mounted away from the tip of the impeller blade.

\section{EXPERIMENTAL FACILITY, Instrumentation, Procedure AND Program}

A low specific speed centrifugal fan test rig was used for the present experimental investigation. Detailed description of the test rig, instrumentation and experimental procedure were presented in Suresh and Sitaram (2019). However for the sake of completeness, these details are briefly presented below. The test rig is a single stage centrifugal fan driven by a $10 \mathrm{HP}$ AC motor whose speed is controlled by a variable speed drive. The schematic layout of the test rig is shown in Fig. 3 and major geometric details of the fan are given in Table 1.

All the pressure measurements needed to determine the pressure rise across the fan were measured using a digital micro manometer (Model FCO012, range \pm $200 \mathrm{~mm}$ of WC, accuracy $\pm 0.1 \%$ full scale reading) and a 20 way scanning box (Model FC0091) manufactured by M/s Furness Control Ltd., UK.
The micro manometer has a $10 \%$ range, corresponding to $\pm 20 \mathrm{~mm}$ of $\mathrm{WC}$. This range was used when the pressures to be measured were below $20 \mathrm{~mm}$ of WC.

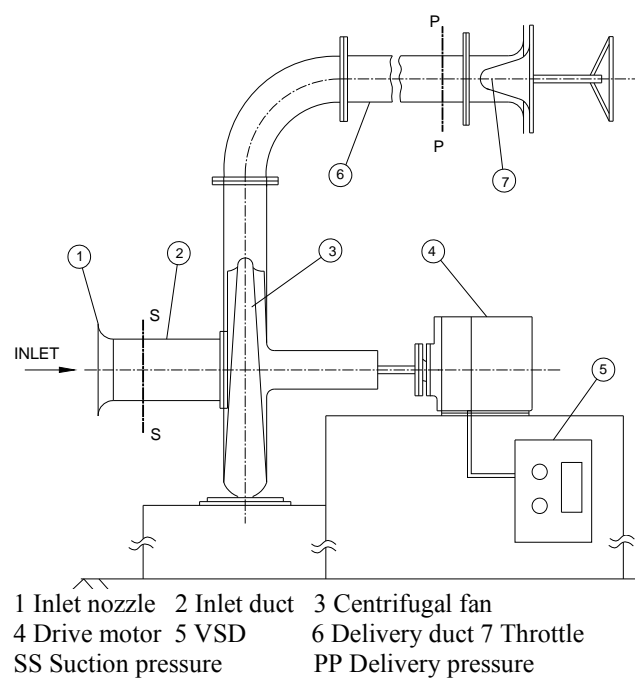

Fig. 3. Schematic layout of the centrifugal fan test rig.

Table 1 Design Details of the Centrifugal Fan Tested

\begin{tabular}{|l|l|}
\hline Pressure ratio, $\mathrm{P}_{\mathrm{O} 2} / \mathrm{P}_{\mathrm{O} 1}$ & 1.036 \\
\hline Mass flow rate, $\mathrm{m}$ & $0.56 \mathrm{~kg} / \mathrm{s}$ \\
\hline Speed, $\mathrm{N}$ & $3,000 \mathrm{rpm}$ \\
\hline $\begin{array}{l}\text { Shape number, } \\
\mathrm{N}_{\mathrm{sh}}=\mathrm{N}(\mathrm{m} / \mathrm{\rho})^{0.5} / 60 \mathrm{~W}^{0.75}\end{array}$ & 0.076 \\
\hline Specific speed, $\mathrm{n}_{\mathrm{q}}=\mathrm{NQ}^{1 / 2} / 60 \mathrm{H}^{3 / 4}$ & $\begin{array}{l}25.3 \\
\mathrm{~m}^{3 / 4} \mathrm{~s}^{3 / 2}\end{array}$ \\
\hline Inducer hub diameter, $\mathrm{D}_{1 \mathrm{~h}}$ & $110 \mathrm{~mm}$ \\
\hline Blade angle at inducer hub, $\beta_{1 \mathrm{~h}}$ & $45 \mathrm{Deg}$. \\
\hline Inducer tip diameter, $\mathrm{D}_{1 \mathrm{t}}$ & $225 \mathrm{~mm}$ \\
\hline Blade angle at inducer tip, $\beta_{1 \mathrm{t}}$ & $29 \mathrm{Deg}$. \\
\hline Impeller exit diameter, $\mathrm{D}_{2}$ & $393 \mathrm{~mm}$ \\
\hline Blade height at exit, $\mathrm{h}_{2}$ & $20 \mathrm{~mm}$ \\
\hline Blade angle at exit, $\beta_{2}$ & $90 \mathrm{Deg}$. \\
\hline Number of impeller blades & 20 \\
\hline Vaneless diffuser exit diameter, $\mathrm{D}_{3}$ & $600 \mathrm{~mm}$ \\
\hline \multicolumn{2}{|c|}{ All angles are w.r.t. tangential direction } \\
\hline
\end{tabular}

As the performance of the fan was to be measured at low rotational speeds (up to $1100 \mathrm{rpm}$ ), the coefficient of discharge of the inlet nozzle was to be determined for very low volume flows. Hence the coefficient of discharge of the inlet nozzle was determined for a few low volume flows. The coefficient of discharge was plotted against the wall static pressure of the inlet nozzle. This plot was curve fitted and the curve fitted equation is used to determine the volume flow. Each performance test of the fan was conducted at constant speed and it 
was measured using a non-contact type tachometer with an accuracy of $\pm 1 \mathrm{rpm}$.

Pressure difference across the pre-calibrated nozzle at the inlet of the test rig was measured to calculate volume flow rate through the fan using the equation, $\mathrm{Q}=\alpha \mathrm{A}(2 \Delta \mathrm{p} / \rho)^{0.5}$.

Volume flow rate was controlled by the throttle downstream of the delivery duct. Two sets of circumferentially mounted static pressure taps, one at the inlet duct (SS) and other at the delivery duct (PP) (see Fig. 3) were used to measure the average static pressure developed cross the fan at each volume flow rate. These measurements are used to determine specific work, W of the fan using the relation,

$\mathrm{W}=\frac{\mathrm{p}_{\mathrm{d}}-\mathrm{p}_{\mathrm{s}}}{\rho}+\frac{\mathrm{c}_{\mathrm{d}}^{2}-\mathrm{c}_{\mathrm{s}}^{2}}{2}+\mathrm{gH}$

All the performance results are plotted in terms of, Energy coefficient, $\psi$, vs. Flow coefficient, $\phi$. The flow coefficient is defined as

$\phi=\mathrm{C}_{\mathrm{m}} / \mathrm{U}_{\mathrm{t}}=\mathrm{Q} / \pi \mathrm{D}_{2} \mathrm{~b}_{2} \mathrm{U}_{2}$

Similarly the head coefficient is defined as,

$\psi=\left(2 \mathrm{~W} / \mathrm{U}_{2}{ }^{2}\right)$

In the present study, quarter round profiles of styrene manufactured by Evergreen scale models are used as Gurney flaps. Height, h of Gurney flap is normalized with the exit blade width, $b_{2}$ and also with the blade spacing at the impeller exit, $s_{2}$. The normalized heights and the notation used for the respective height in the results is given in Table 2. Gurney flaps are attached to the impeller blades pressure surface at the tip using Feviglue instant glue. Figure 4(a) shows the fan impeller which is a radial exit impeller with an inducer. Figure 4(b) shows impeller blade with Gurney flaps of different heights mounted at different positions. Gurney flaps of different heights at different positions are schematically shown in Fig. 5. In this figure, the height of Gurney flap is scaled with thickness of the impeller blade at its tip which is $3 \mathrm{~mm}$. All the performance tests were carried out on the centrifugal fan at five different rotational speeds.
The corresponding blade tip speed, $\mathrm{U}_{2}$ and Reynolds number based on both impeller blade height at exit $\left(b_{2}\right)$ and impeller exit diameter $\left(D_{2}\right)$ are listed in Table 3 for the corresponding tested speed.

Based on the manufacturer's specifications of different instruments used, the total measurement error in the determination of flow coefficient can be estimated as $1 \%$ at high volume flows. However at low volume flows, particularly when the fan is operating at the lowest rotational speed, the total measurement error can be as high as $4 \%$. The error in measurement of head coefficient depends on the accuracy of measurement of static pressure across the fan, air density and impeller speed. The total measurement error in the determination of head coefficient can be estimated as $0.7 \%$ at high volume flows, when the pressure rise is high. However at low volume flows, particularly when the fan is operating at the lowest rotational speed, the total measurement error can be as high as $3 \%$.

Table 2 Details of Gurney flaps tested

\begin{tabular}{|l|c|c|c|}
\hline \multicolumn{1}{|c|}{ Notation } & $\begin{array}{c}\mathrm{h} \\
(\mathrm{mm})\end{array}$ & $\begin{array}{c}\mathrm{h} / \mathrm{b}_{2} \\
(\%)\end{array}$ & $\begin{array}{c}\mathrm{h} / \mathrm{s}_{2} \\
(\%)\end{array}$ \\
\hline $\begin{array}{l}\text { H0 Baseline } \\
\text { (Fan w/o GF) }\end{array}$ & 0.0 & 0.0 & 0.00 \\
\hline $\mathrm{H} 1$ & 1.0 & 5.0 & 1.62 \\
\hline $\mathrm{H} 2$ & 1.5 & 7.5 & 2.43 \\
\hline $\mathrm{H} 3$ & 2.0 & 10.0 & 3.24 \\
\hline $\mathrm{H} 4$ & 2.5 & 12.5 & 4.05 \\
\hline
\end{tabular}

Table 3 Details of blade tip speeds and Reynolds numbers at which fan is tested

\begin{tabular}{|c|c|c|c|c|}
\hline $\begin{array}{c}\text { Notation } \\
\text { used }\end{array}$ & $\begin{array}{c}\text { Speed, } \\
\mathrm{N} \\
(\mathrm{rpm})\end{array}$ & $\begin{array}{c}\mathrm{U}_{2} \\
(\mathrm{~m} / \mathrm{s})\end{array}$ & $\mathrm{Re}_{\mathrm{b} 2}$ & $\operatorname{Re}_{\mathrm{D} 2}$ \\
\hline $\mathrm{Re} 1$ & 1100 & 22.6 & $0.30 \times 10^{5}$ & $0.59 \times 10^{6}$ \\
\hline $\mathrm{Re} 2$ & 1500 & 30.9 & $0.41 \times 10^{5}$ & $0.81 \times 10^{6}$ \\
\hline $\mathrm{Re} 3$ & 2000 & 41.2 & $0.55 \times 10^{5}$ & $1.08 \times 10^{6}$ \\
\hline $\mathrm{Re} 4$ & 2500 & 51.4 & $0.69 \times 10^{5}$ & $1.35 \times 10^{6}$ \\
\hline Re5 & 2900 & 59.7 & $0.80 \times 10^{5}$ & $1.57 \times 10^{6}$ \\
\hline
\end{tabular}
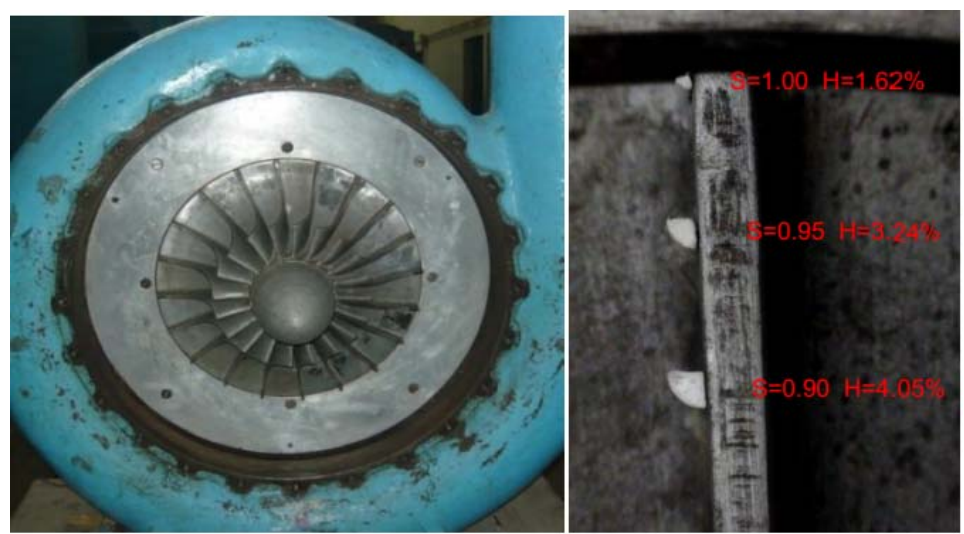

Fig. 4. Centrifugal fan impeller blade with Gurney flap (a) Front view of the impeller (b) Gurney flap mounted on the pressure surface of the impeller tip (Note that three Gurney flaps of different heights are shown at three different mounting positions. Only one Gurney flap of same height is mounted at any one of the positions on all the blades at any time). 

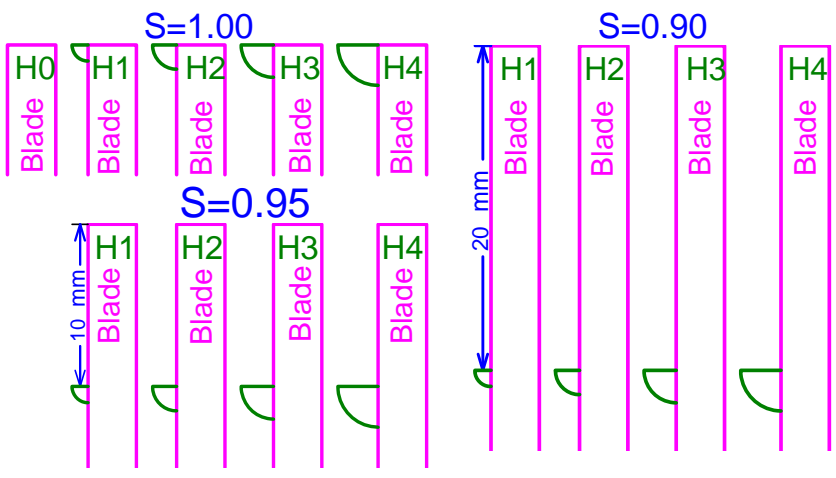

Fig. 5. Gurney flaps at different positions on the impeller blade of the centrifugal fan.

\section{RESUltS AND DisCUSSIONS}

\subsection{Effect of Reynolds Number on the Head Coefficient of the Fan}

Figure 6 presents the performance curves of the baseline fan plotted in terms of non-dimensional parameters, $\psi$ vs. $\phi$ for the five Reynolds numbers in the order of Re1 to Re5. For the sake of brevity only representative plots are presented. The effect of Reynolds number on the head coefficient $(\psi)$ for the baseline fan is substantial. The reasons for the drop in the efficiency of the centrifugal compressors at low Reynolds numbers and correlations for the loss in efficiency are provided by many researchers, the latest being by Casey and Robinson (2011). Recently Tiainen (2018) identified that losses in the boundary layers of the hub and shroud and tip leakage flow increase rapidly with reduction in the operating Reynolds number.

The effect of Reynolds number on the head coefficient $(\psi)$ for the fan with Gurney flap is almost negligible. Gurney flap increases the effective camber of the impeller blade and the flow turning is higher compared to that of the basic impeller. Hence the flow becomes more turbulent reducing the effects of low Reynolds numbers. The increase in the effective camber also increases the tangential velocity. Hence both the slip factor and head coefficient increase. This is true for the performance of the fan with Gurney flaps of different heights and different mounting positions. However as Gurney flap is moved upstream of the impeller blade tip, the head coefficient is reduced and is sometimes lower than that of the baseline fan.

To determine the values of peak head coefficient and the corresponding flow coefficient, the following procedure is adopted. The performance curves are curve fitted using second order polynomial degree. For curve fitting only $\psi$ values in the range of $\phi=0.2$ to 0.6 are used. The curve fitted equation is differentiated wrt $\phi$ and the value of $\phi$ when $d \psi / d \phi$ is zero is taken as $\phi_{\text {peak. }}$ Values of $\psi_{\text {peak }}$ and $\psi$ at $\phi_{\text {design }}$ are calculated from the curve fitted equations. This procedure eliminates any minor measurement errors. Figure 7 compares experimental $\psi$ vs. $\phi$ performance curves with the curve fitted ones for the fan performance without Gurney flap at the five Reynolds numbers. The difference between the measured and curve fitted values of $\psi$ is always within $\pm 0.5 \%$, except at a few points particularly at low speeds. Also $\psi_{\text {peak }}$ and $\phi_{\text {peak }}$ are marked in the figure.

The maximum increase in the peak head coefficient and the head coefficient at design coefficient $\left(\phi_{\text {design }}=0.34\right)$ is $3.5 \%$ and $3.2 \%$ respectively for the baseline fan as Reynolds number increases from Re1 to Re5. However for the fan with Gurney flaps, the effect of Reynolds number on the performance is negligible (about $0.5 \%$ drop in $\psi_{\text {peak }}$ and $\psi$ at $\left.\phi_{\text {design }}\right)$ and this is true for all the heights and the mounting positions tested. These results on Reynolds number dependency are similar to the one pointed out by Dundi et al. (2012). The value of flow coefficient at the peak head coefficient shifts to the right as Reynolds number increases. This change is $4.9 \%(0.018)$ from $\operatorname{Re} 1$ to Re5.

\subsection{Effect of Gurney Flap Height on the Head Coefficient of the Fan}

Performance ( $\psi$ vs. $\phi$ ) curves of the fan with Gurney flaps of different heights mounted at different positions are compared with the performance curves of the baseline fan in Fig. 8 at different Reynolds numbers. The $\psi$ vs. $\phi$ curves are presented in three sets: one for each mounting position of Gurney flap. In each set, the performance curves of the fan for the baseline and fan with Gurney flap of four different heights are presented together for one Reynolds number.

At $S=1.00$ (Gurney flap mounted on the impeller blade tip), head coefficient increases substantially compared to that for the baseline fan. The improvement is maximum at the lowest Reynolds number. As Reynolds number increases, the improvement in the performance curves is reduced. At the highest Reynolds number, the improvement is nominal. When Gurney flap of H1 height is mounted at the impeller tip, the increase in the performance of the fan is substantial. With further increase in the height of Gurney flap, the improvement is still substantial. 
M. Suresh and N. Sitaram/ / JAFM, Vol. 15, No. 1, pp. 255-269, 2022.

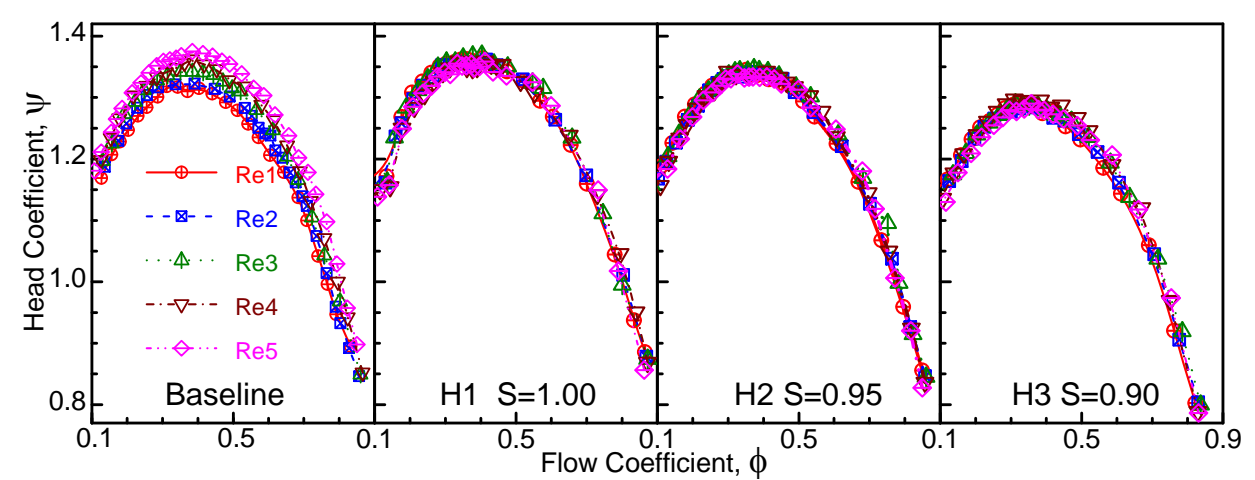

Fig. 6. Effect of Reynolds number on the head coefficient of the centrifugal fan.

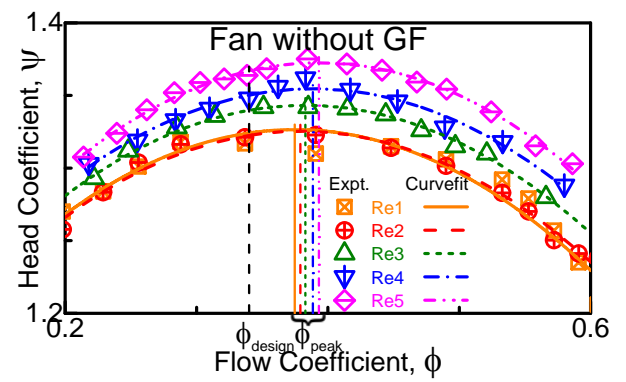

Fig. 7. Procedure to determine peak head coefficient of the centrifugal fan.
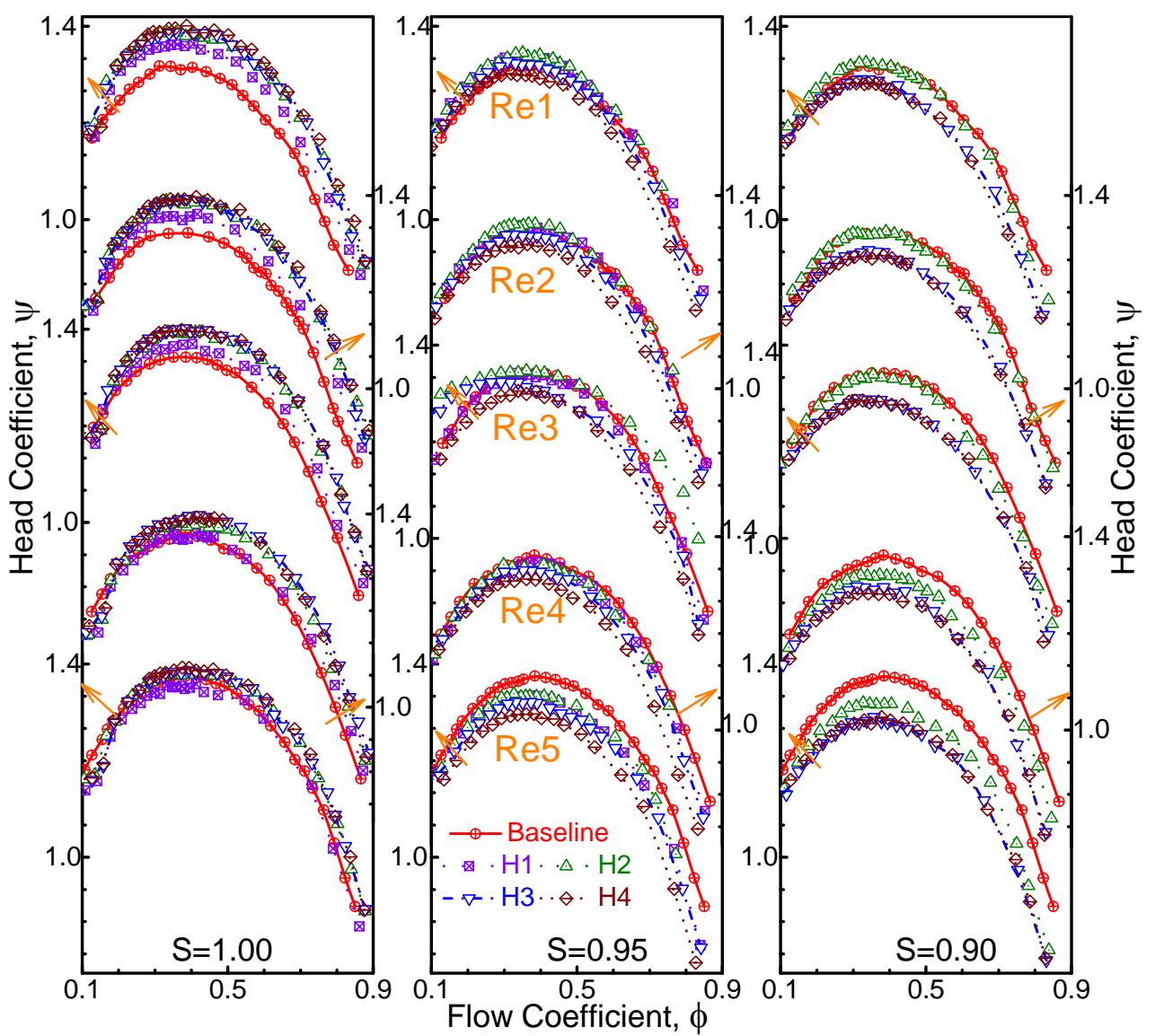

Fig. 8. Effect of Gurney flap height on the head coefficient of the centrifugal fan. 
One of the possible reasons for improvement in the performance curve is due to increase in the effective camber of the impeller blade. Although the effective camber increases as the height of Gurney flap is increased, the increase may not be proportional to the height of Gurney flap. Also the friction on Gurney flap increases as the height of Gurney flap is increased. At Reynolds number of $\mathrm{Re} 4$, the performance of the baseline fan and fan with Gurney flap of H1 height is almost identical. Although the performance of the fan with the height of $\mathrm{H} 2$ is higher than that of the baseline fan, further increase in the height of Gurney flap does not improve the performance.

At Reynolds number of Re5, similar observation is made. But the performance of the fan with Gurney flap of $\mathrm{H} 1$ height is lower than that of the baseline fan. Hence it may be concluded that the optimum height of Gurney flap for this fan is $\mathrm{H} 2(1.5 \mathrm{~mm})$, although Gurney flaps of height greater than $\mathrm{H} 2$ can be used without any penalty. The maximum volume flow passing through the fan also increases when Gurney flap is mounted on the impeller blade tip.

From the figure, it can be observed that the performance of the fan with Gurney flap mounted away from the impeller tip decreases. For $S=0.95$, marginal fan performance improvement is observed for Gurney flap with lower two heights, while the fan performance with larger Gurney flaps is below that of basic configuration. At higher Reynolds number, the performance of the fan with Gurney flap is below that of the basic fan. However performance is slightly better when Gurney flap is mounted at $\mathrm{S}=0.90$. The most probable reason is that the effective camber is reduced and the losses after Gurney flap increase as there is reduced scope to mix with the main flow. It is also quite possible that the flow separates after Gurney flap.

\subsection{Effect of Gurney Flap Position on the Head Coefficient of the Fan}

To compare the effect of mounting position of Gurney flap, it is essential to present the $\psi$ vs. $\phi$ curves of the fan at different mounting positions including that of the baseline fan together at a particular Reynolds number and at a particular height of Gurney flap. These $\psi$ vs. $\phi$ curves are presented in Fig. 9 in four sets, one each for each height of Gurney flap. In each set, the $\psi$ vs. $\phi$ curves are presented together for one Reynolds number.

As expected the $\psi$ vs. $\phi$ curves of the fan with Gurney flap mounted at the impeller blade tip is always maximum. As Reynolds number is increased, the performance improvement due to Gurney flap is reduced with zero or nominal performance improvement at the highest Reynolds number. The performance of the fan with Gurney flap mounted at $\mathrm{S}=0.90$ is always lower than that of the fan with Gurney flap mounted at $S=0.95$. However the difference between the performance curves for these two positions is very small. Furthermore it has been noticed that the performance with Gurney flap mounted at $S=0.90$ is always lower than that of the baseline fan. It is understandable as the effective camber is increased with Gurney flap, it introduces additional frictional losses. However it may be still worth to carry out this investigation on a centrifugal fan having thin blades with Gurney flaps mounted closer to the tip with the mounting position varied in smaller intervals, $2 \%$ of tip radius.

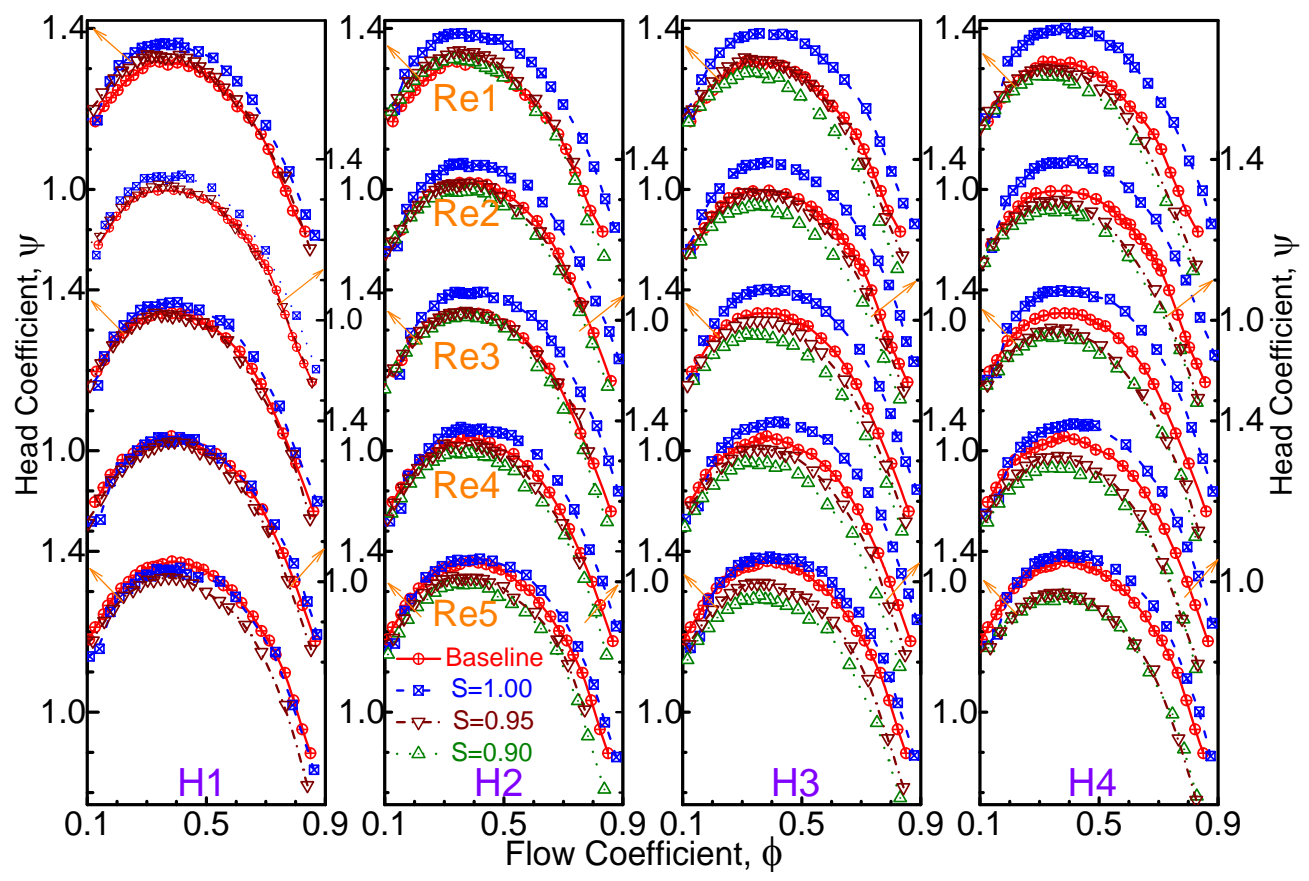

Fig. 9. Effect of Gurney flap mounting position on the head coefficient of the centrifugal fan. 


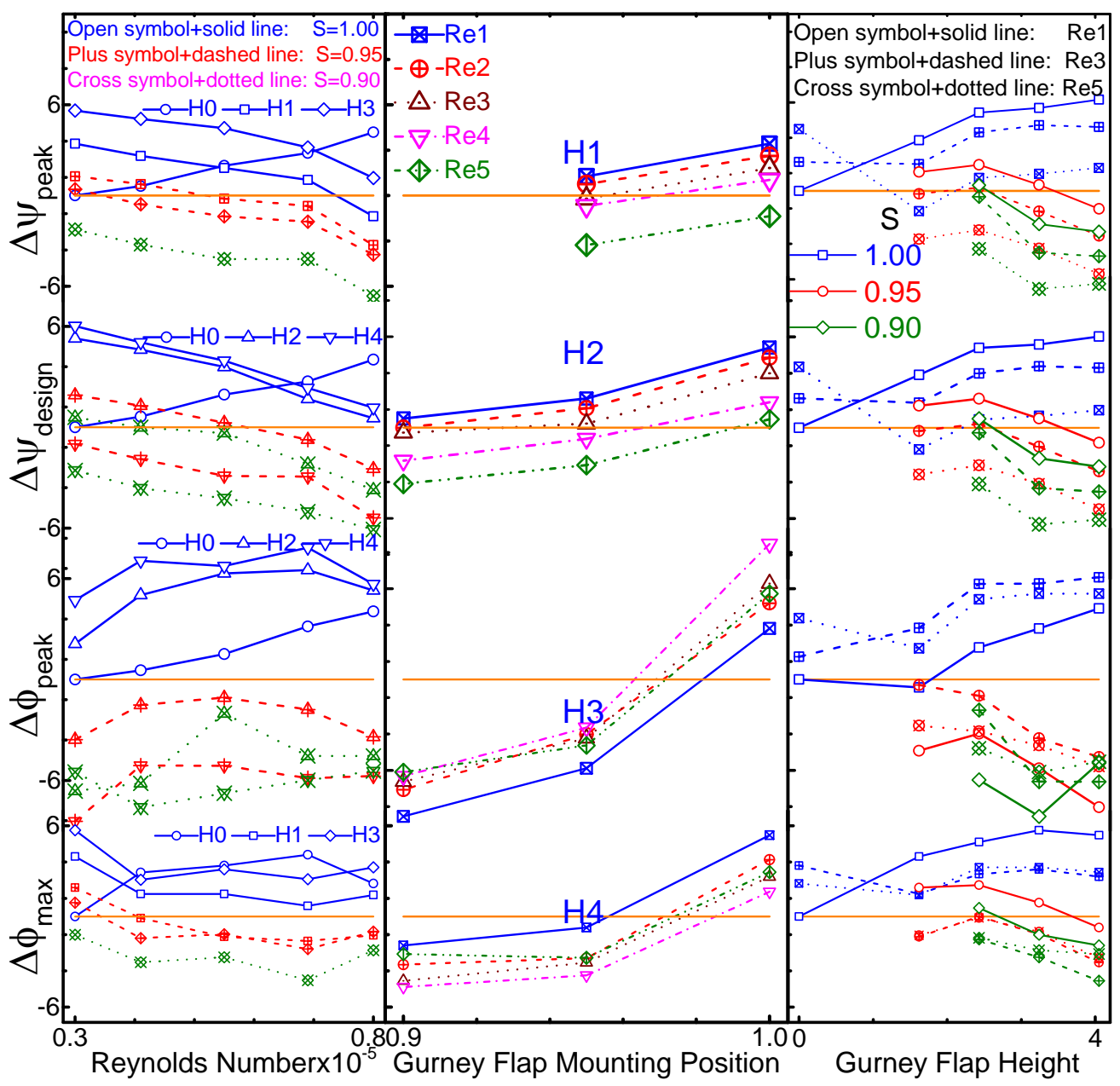

Fig. 10. Effect of Reynolds number, Gurney flap mounting position and Gurney flap height on the important performance parameters of the centrifugal fan

The maximum volume flow passing through the fan decreases when Gurney flap is mounted upstream of the impeller blade tip. The possible reason is the effective throat is reduced when Gurney flap is mounted upstream of the impeller blade tip. As Gurney flaps are mounted upstream of the impeller blade tip, the performance of the fan is reduced. Many times the performance of the fan falls below that of the baseline fan. These results are presented and discussed below.

\subsection{Effect of Reynolds number, Gurney Flap Height and Position on Important Performance Parameters of the Fan}

The most important performance parameters, such as peak head coefficient, head coefficient at design flow coefficient, flow coefficient where peak head coefficient occurs and maximum flow coefficient are discussed here. The percentage increases in these parameters as a function of Reynolds number, Gurney flap height and position are presented in
Fig. 10. For the baseline fan, the reference value is taken as the value at the lowest Reynolds number. For the fan with Gurney flap, the reference value is taken as the value of the baseline fan at the corresponding Reynolds number.

The following equations are used to compute the percentage change in $\psi_{\text {peak }}$.

$$
\begin{aligned}
\Delta \psi_{\text {peak }}= & \left(\psi_{\text {peak }}-\psi_{\text {peak at Re1 } 1}\right) / \psi_{\text {peak }} \times 100 \\
& \text { for baseline fan } \\
\Delta \psi_{\text {peak }}= & \left(\psi_{\text {peak }}-\psi_{\text {peak for baseline fan }}\right) / \psi_{\text {peak }} \times 100 \\
& \text { for fan with Gurney flap }
\end{aligned}
$$

Both the values of $\psi_{\text {peak }}$ for the baseline fan and fan with Gurney flap are taken at the same Reynolds number. Similar definitions are used for other performance parameters.

The procedure similar to that adopted to find $\psi_{\text {peak }}$ for basic configuration (Fig. 7) is also adopted to determine the values of $\phi_{\text {peak }}, \psi_{\text {peak }}$ and $\psi_{\text {design }}$. 
For sake of brevity, only the percentage change in the performance parameters are presented at the three important Reynolds numbers, viz. the lowest, middle and the highest Reynolds numbers (Re1, Re3 and Re5 respectively) in the figure showing effect of Gurney flap height on the performance parameters.

In all the figures, orange line with a value of 0 corresponds to zero percentage change. If the curve is above this line, it implies that Gurney flap improves the performance. Alternatively, if the curve is below this line, it implies that Gurney flap deteriorates the performance.

The percentage change in peak head coefficient, $\Delta \psi_{\text {peak }}$ decreases more or less linearly as Reynolds number increases. The maximum values are obtained for the fan with Gurney flap of height $\mathrm{H} 4$ mounted at the impeller blade tip followed by fan with Gurney flaps of reducing height. The difference in the value of $\Delta \psi_{\text {peak }}$ for the fans with Gurney flap of height equal or higher than $\mathrm{H} 2$ is nominal while this value is considerably lower for the fan with Gurney flap of height of $\mathrm{H} 1$. The trend of maximum values of $\Delta \psi_{\text {peak }}$ occurring for Gurney flap of height H4 is reversed when Gurney flap is mounted at $\mathrm{S}=0.95$ and $\mathrm{S}=0.90$. That is maximum values of $\Delta \psi_{\text {peak }}$ occurs at the lowest value of Gurney flap height followed by Gurney flaps of reducing height. When Gurney flap is mounted at $\mathrm{S}=0.95$, the value of $\Delta \psi_{\text {peak }}$ is sometimes positive and sometimes negative depending upon the height of Gurney flap and Reynolds number. When Gurney flap is mounted at $\mathrm{S}=0.90$, the value of $\Delta \psi_{\text {peak }}$ is always negative indicating reduction in $\psi_{\text {peak }}$ compared to that of the fan without Gurney flap.

The percentage change in maximum flow coefficient, $\Delta \phi_{\max }$ is always positive when Gurney flap is mounted at $\mathrm{S}=1.00$. The maximum volume flow passing through the fan increases when Gurney flap is mounted at $\mathrm{S}=1.00$ for all values of Reynolds number and all heights of Gurney flap. The values are more or less equal for all values of Reynolds number and all heights of Gurney flap.

The values are more or less equal for all values of Reynolds number and all heights of Gurney flap. When Gurney flap is mounted at $S=0.90$, the value of $\Delta \phi_{\max }$ is positive at the lowest Reynolds number but negative at higher Reynolds numbers indicating loss in maximum volume flow that can be passed through the fan. When Gurney flap is mounted at $\mathrm{S}=0.95$, the value of $\Delta \phi_{\max }$ is always negative indicating reduction in $\phi_{\max }$ compared to that of the fan without Gurney flap. The percentage change in the flow coefficient, $\Delta \phi$ at the peak head coefficient is always near zero or negative for all positions of Gurney flap. However when Gurney flap is mounted at $S=1.00$, this percentage change is very little indicating that the loss in the operating range of the fan is minimum. The loss in this percentage is highest when Gurney flaps are mounted at $\mathrm{S}=0.9$, indicating that the penalty in the operating range of the fan is high. When Gurney flaps are mounted at $\mathrm{S}=0.95$, this loss is moderate falling in between that of $\mathrm{S}=1.00$ and $\mathrm{S}=0.90$.

The percentage change in head coefficient at design flow coefficient, $\Delta \psi_{\text {design }}$ follows same trends of $\Delta \psi_{\text {peak }}$ with almost the same magnitudes.

As the height of Gurney flap increases, $\Delta \psi_{\text {peak }}$ increases rapidly first and then increases slowly. However this trend is not followed for the highest Reynolds number. For high Reynolds numbers, the value at the lowest Reynolds number is used as reference. Even for the fan without Gurney flap, $\Delta \psi_{\text {peak }}$ is positive. As Gurney flap is moved upstream of the impeller blade tip, the value of $\Delta \psi_{\text {peak }}$ is reduced and negative when $\mathrm{S}=0.95$ at all Reynolds numbers. This is clearly shown in the adjoining figure where the value of $\Delta \psi_{\text {peak }}$ is plotted against $\mathrm{S}$ for Gurney flap height of $\mathrm{H} 2$. At the five Reynolds numbers, the value of $\Delta \psi_{\text {peak }}$ is minimum when $S=0.90$. Similar observations are made for other performance parameters.

The variation in the performance parameters with the Gurney flap mounting position, $\mathrm{S}$ is more or less linear at all Reynolds numbers for all the Gurney flap heights. However the change in the performance of the fan with Gurney flap at $S=0.90$ and $\mathrm{S}=0.95$ is lower than the change in the performance of the fan with Gurney flap at $S=0.95$ and $S=1.00$. Furthermore it is observed that the change in the fan performance with the mounting positions is higher for the fan with Gurney flap of height of $\mathrm{H} 3$. The maximum value always occurs when Gurney flap is mounted at the impeller blade tip $(\mathrm{S}=1.00)$ and the minimum value occurs when the Gurney flap is mounted at $\mathrm{S}=0.90$.

The above data is replotted with $\mathrm{S}$ on the $\mathrm{x}$-axis for three values of Reynolds numbers, viz. Re1 (lowest Reynolds number, where Gurney flap has considerable effect on the fan performance), Re2 (medium Reynolds number, where Gurney flap has moderate effect on the fan performance), and Re5 (highest Reynolds number, where Gurney flap has negligible effect on the fan performance) and presented in Fig. 11.

From the figure, it is evident that the performance parameters decrease more or less linearly as the mounting position of Gurney flap is moved away from the impeller blade tip. When Gurney flap is at $\mathrm{S}=1$ (impeller blade tip), the performance of the fan always improves at the lowest Reynolds number, while the performance improvement is modest at the medium Reynolds number and the performance improves nominally or deteriorates slightly at the highest Reynolds number. When Gurney flap is mounted at $\mathrm{S}=0.95$, the performance improvement is nominal even at the lowest Reynolds number. When Gurney flap is mounted at $\mathrm{S}=0.90$, the performance always deteriorates. Hence it is always preferable to mount Gurney flap as close as to the impeller blade tip. 


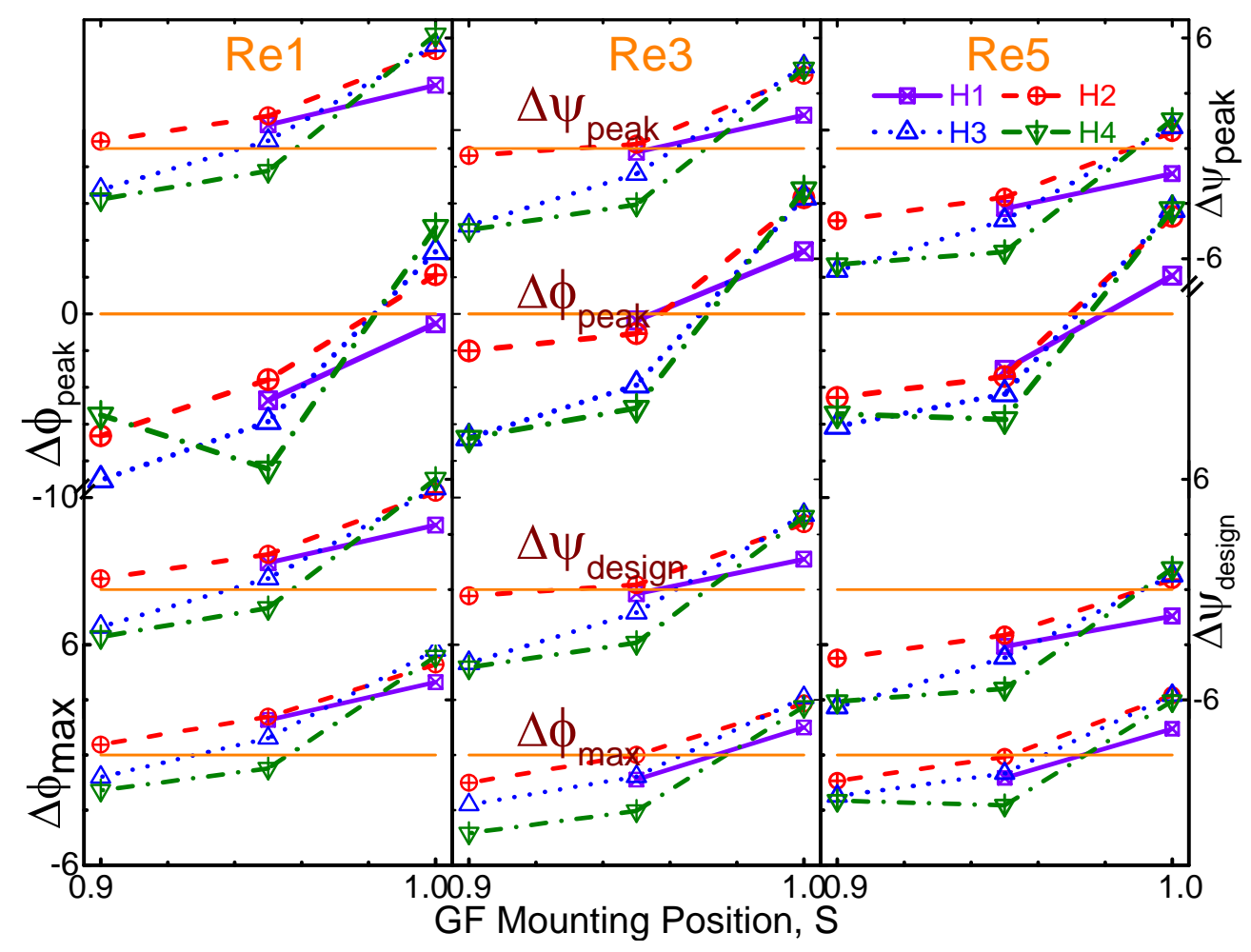

Fig. 11. Variation of important performance parameters of the centrifugal fan with Gurney flap mounting position at different Reynolds numbers and Gurney flap heights

\section{CONCLUSIONS}

The following major conclusions are drawn from the present experimental investigation on the effects of height and position of Gurney flap applied for a centrifugal fan impeller.

The effect of Reynolds number on the head coefficient is negligible for the tested fan with Gurney flap, while the effect of Reynolds number on the head coefficient of the fan without Gurney flap is considerable. Both peak head coefficient and the head coefficient at design coefficient increase by about $4 \%$ for the fan without Gurney flap as Reynolds number increases from Re1 to Re5. The fan head coefficient increases with Gurney flaps and the maximum volume flow across the fan also increases with Gurney flap at low Reynolds numbers and increases slightly at higher Reynolds number compared to the baseline fan. As the height of Gurney flap increases the head coefficient of the fan increases. However the increase is not proportional to the height of Gurney flap. As the height increases, the fan head coefficient increases at a slow rate. The improvement in the fan head coefficient is maximum when Gurney flaps are mounted at $S=1.00$. When Gurney flaps are mounted at $S=0.95$, the head coefficient is deteriorated rapidly and always lower than that of the baseline fan. When Gurney flaps are mounted at $\mathrm{S}=0.90$, there is some improvement in the head coefficient of the fan compared to the performance of the baseline fan. This improvement depends on Gurney flap height and Reynolds number. The head coefficient increases at low
Reynolds numbers of Re1 to Re3 for Gurney flap heights upto $\mathrm{H} 2$, while the head coefficient deteriorates at high Reynolds numbers for all Gurney flap heights. At larger Gurney flap height, the head coefficient is lower than that of the head coefficient of the baseline fan even at lower Reynolds numbers.

\section{References}

Bao, N., H. Ma and Z. Ye (2000) Experimental study of wind turbine blade power augmentation using airfoil flaps, including the Gurney flap. Wind Engineering 24, 25-34.

Brown, L. and A. Filippone (2003). Aerofoil at low speeds with Gurney flap. The Aeronautical Journal 107 (1075), 539-546.

Byerley, A. R., O. Störmer, J. W. Baughn, T. W. Simon, K. W. Van Treuren and J. List (2003). Using Gurney flaps to Control Laminar Separation on Linear Cascade Blades. ASME Journal of Turbomachinery 125 (1), 114-120.

Casey, M. V. and C. J. Robinson (2011). A unified correction method for Reynolds number, size and roughness effects on the performance of compressors. Proc. Inst. Mech. Engineers, 225 Part A: J. Power and Energy, 864-876.

Chakroun, Y. and G. Bangga (2021). Aerodynamic Characteristics of Airfoil and Vertical Axis Wind Turbine Employed with Gurney flaps. Sustainability 13, 4284, 22. 
Chen, P. H., W. Y. Qiao and H. L. Luo (2010). Investigation of low solidity LP turbine cascade with flow control: Part 2-Passive flow control using Gurney flap. ASME Paper GT2010-22330.

Chen, L., H. Xie, J. Xu, R. Dai and J. Chen (2018). Experimental and numerical study on the performance of an axial fan with a Gurney flap. Advances in Mechanical Engineering 10(10), 117.

Cole, J., B. Vieira, J. Coder, A. Premi and M. Maughmer (2013). Experimental investigation into the effect of Gurney flaps on various airfoils. Journal of Aircraft 50(4), 1287-1294.

Dundi, T. M. K., N. Sitaram and M. Suresh (2012). Application of Gurney flaps on a Centrifugal Fan Impeller, Paper O12008S. International Journal of Fluid Machinery and Systems 5(2), 65-71.

Gai, S. L. and R. Palfrey (2003). Influence of trailing-edge flow control on airfoil performance. Journal of Aircraft 40(2), 332-337.

Giguere, P., G. Dumas and J. Lemay (1997). Gurney flap scaling for optimum lift-to-drag ratio. Journal of Aircraft 35(12), 1888-1890.

Greenblatt, D. (2011). Application of Large Gurney flaps on Low Reynolds Number Fan Blades. ASME Journal of Fluids Engineering 133, 021102-1 to 021102-7.

Graham, M., M. Adrian and L. W. Traub (2018). Experimental Study on the Effect of Gurney flap Thickness on Airfoil Performance. Journal of Aircraft 55(2), 897-902.

Jain, S., N. Sitaram and S. Krishnaswamy (2015). Computational investigations on the effects of Gurney flap on airfoil aerodynamics. International Scholarly Research Notices, Volume 2015, Article ID 402358, 11 pages.

Janus, J. M. (2000). Analysis of Industrial Fan Designs with Gurney flaps. AIAA Paper 2000-983.

Kim, M. J., S. M. Jang, J. H. Kim and S. J. Song (2013). Effect of Gurney flaps on radial fan blades - Mechanisms of performance enhancement. Paper ID: AICFM12-000125, The $12^{\text {th }}$ Asian International Conference on Fluid Machinery, Yogyakarta, Indonesia.

Kim, M. J., S. M. Jang, S. H. Son and S. J. Song (2014). Effect of Gurney flaps on Performance of a Radial Fan. Paper ID: ACGT2014-0134, Asian Congress on Gas Turbines, Seoul, Korea.

Lee, T. (2009). Aerodynamic Characteristics of Airfoil with Perforated Gurney-Type Flaps. Journal of Aircraft 46(2), 542-548.

Li, Y. C., J. J. Wang and P. F. Zhang (2002). Effect of Gurney flaps on a NACA0012 airfoil. Flow Turbulence and Combustion 68, 27-39.

Li, Y. C., J. J. Wang and P. F. Zhang (2003). Influences of mounting angles and locations on the effects of Gurney flaps. Journal of Aircraft 40(3), 494-498.

Liebeck, R. H. (1978). Design of subsonic airfoils for high lift, Journal of Aircraft 15(9), 547-561.

Maughmer, M. D. and G. Bramesfeld (2008). Experimental Investigation of Gurney flaps. Journal of Aircraft 45(6), 2062-2067.

Mudassir, Ahmed, M. R. and Q. H. Nagpurwala (2016). Performance enhancement of a transonic axial compressor stage with Gurney flaps at rotor blade trailing end. Paper ACGT2016-004, Proc. of the Asian Congress on Gas Turbines, Mumbai, India.

Mudassir, Ahmed, M. R. and Q. H. Nagpurwala (2018). Effect of Chordwise Location of Full Span Gurney flap on Aerodynamic Performance of a Transonic Axial Compressor Rotor. Proc. of 20th Annual CFD Symposium, Bengaluru, India.

Mudassir, Ahmed, M. R., Q. H. Nagpurwala and S. Subbaramu (2014). Numerical studies on the effect of Gurney flap on aerodynamic performance and stall margin of a transonic axial compressor rotor. Paper No. GTINDIA2014-8130, Proc. of ASME Gas Turbine India Conference, New Delhi, India.

Myose, R. Y., J. C. Lietsche, D. Scholz, H. Zinge, S. Hayashibara and I. Heron (1996). Flow Visualization Study on the Effect of a Gurney flap in a Low Reynolds Number Compressor Cascade. AIAA Paper 2006-7809.

Syawitri, T. P., Y. F. Yao, J. Yao and B. Chandra (2020). The effect of Gurney flap on flow characteristics of vertical axis wind turbine. International Journal of Modern Physics B, 34 (14-16) 2040107, 5 pp.

Son S., J. Kim and M. Kim (2017). Centrifugal fan and air conditioner using the same. US Patent No. 9,611,860.

Suresh, M. and N. Sitaram (2014). Effect of Gurney Flap Height on the Performance of a Centrifugal Fan, Paper ID: NCETET-208, National Conference on Emerging Trends in Engineering \& Technology, Rajasthan, India.

Suresh, M. and N. Sitaram (2019). Effect of Gurney Flap Configuration on the Performance of a Centrifugal Fan. Journal of Applied Fluid Mechanics 12(2), 565-571.

Tamagawa, T. and Y. Yoshida (2006). Centrifugal Fan, Cooling Mechanism and Apparatus Furnished with the Cooling Mechanism. US Patent No. US20060056964A9.

Tatpatti, G., N. Sitaram and K. Viswanath (2021). Computational and experimental investigations of separation control of LP turbine cascade blades using Gurney flaps. Journal of Applied Fluid Mechanics 14(3), 779-792.

Tiainen, J. (2018). Losses in low Reynolds number centrifugal compressors. Ph. D. Thesis, Lappeenranta University of Technology, Finland. 
M. Suresh and N. Sitaram/ / JAFM, Vol. 15, No. 1, pp. 255-269, 2022.

Traub, L. W. (2017). Effect of Gurney flaps on an Elliptical Airfoil. ASME Journal of Fluids Engineering 139, 101102-1 to 101102-9.

Traub, L. W., A. C. Miller and O. Rediniotis (2006). Preliminary Parametric Study of Gurney-Flap Dependencies. Journal of Aircraft 43(4), 1242-1244.

Troolin, D. R., E. K. Longmire and W. T. Lai (2006). Time resolved PIV analysis of flow over a NACA0015 airfoil with Gurney flap Experiments in Fluids 41(2), 241-254.
Ueno, S. (2010). Investigation of a Plasma Gurney flap for Lift Enhancement, MASc Thesis, Montreal University, Canada.

Wang, J. J., Y. C. Li and K.-S. Choi (2008). Gurney flap: Lift Enhancement, Mechanisms and Applications. Progress in Aerospace Sciences 44, 22-47.

Zhang, Ye, V. Ramdoss, Z. Saleem, X. Wang, G. Schepers and C. Ferreira (2019). Effects of root Gurney flaps on the aerodynamic performance of a horizontal axis wind turbine. Energy 187, 115955, $12 \mathrm{pp}$. 